\title{
Teaching Cases On Conflicts Of Interest In The Workplace: How To Avoid Ethical Dilemma
}

Tim Kizirian, (Email: tkizirian@csuchico.edu), California State University, Chico Wallace Leese, (Email: wleese@ csuchico.edu), California State University, Chico Samir Nissan, (Email: snissan@csuchico.edu), California State University, Chico

\section{OVERVIEW}

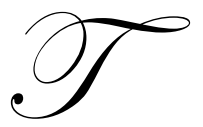

his paper presents three teaching cases on common types of conflicts of interest in the workplace: (1) fraternization (supervisor-subordinate dating), (2) nepotism, and (3) when a relative or friend is employed by a supplier or customer. These short case studies can be used in the classroom to explore the difficult issues that accompany conflicts of interest in the workplace. It is envisioned that these three cases will generate classroom discussion at a level appropriate for an undergraduate business course dealing with ethical issues caused by conflicts of interest.

When employees mix personal and business interests, conflicts of interest will eventually arise. A conflict of interest exists when an employee's loyalties or actions are divided between the employer's interests and those of another person or entity, such as a family member, a supplier, or a customer. Both an actual conflict of interest and the appearance of a conflict of interest should be avoided. Despite best intentions, these conflicts of interest will likely negatively affect both the employee and the employer. The mere appearance of behavior adverse to the employer may impact business performance and workplace morale. This paper discusses conflicts of interest involving personal and business relationships and provides practical guidance on how to avoid those relationships. Conflict of interest problems can easily manifest themselves when transactions are not at arms length.

\section{CASE \#1：FRATERNIZATION}

This fraternization case, slightly modified, was taken from Heinze et al (2004).

\section{Case Facts}

- $\quad$ Sam and Sally are peers in the same accounting firm and are scheduled on many of the same audits. After working together for six weeks on an audit, they developed a romantic relationship outside of work.

- $\quad$ To maintain their privacy and avoid gossip, Sam and Sally agree to keep the personal relationship as quiet as possible and refrain from publicly displaying affection at work. Sam and Sally are confident that their relationship is not common knowledge within the firm.

- In the fall, Sally is promoted to a managerial position. In Sally's new role, she will manage Pat. Pat will manage Sam as Sam's senior on several key audit engagements.

- $\quad$ Because Sally will not be directly managing Sam, she and Sam decide to continue to keep the relationship secret. Both are certain that the relationship will not cause any issues within the audit team and that no actual conflicts of interest will occur. Sally is not directing or reviewing Sam's work at a detailed level and they know they can maintain a purely professional relationship at work.

\section{Discussion Guiding Questions}

- $\quad$ Did a conflict of interest exist before Sally was promoted?

- Does a conflict of interest exist now that Sally has a managerial position within the accounting firm? 
- What are the implications of disclosure vs. non-disclosure of the relationship to Sally and Sam?

- Which is a bigger conflict of interest concern: the relationship or the failure to disclose the relationship?

- Assuming that the relationship is disclosed, what are the implications of the mere appearance of a conflict of interest caused by the relationship on the behavior of Sally, Sam, and Pat?

- As partner in charge of the accounting firm, how would you address and resolve the conflict of interest problems?

\section{Teaching Notes}

A stated by Heinze et al (2004), Sally's conduct probably violates her firm's rules on fraternization. Supervisors who pursue romantic relationships with subordinates usually do so in violation of their firm's principles of conduct and guidelines to behavior. Since most employees will spend more time interacting with colleagues than they will spend with people outside the company, workplace dating and intimacy is a natural and likely outcome. While most firms do not generally prohibit workplace dating, they do prohibit managers from pursuing romantic or sexual relationships with employees whom they supervise. Involved managers need to take steps immediately to end the supervisory relationship. The notion of supervision extends to anyone within the manager's direct or indirect chain of supervision. Manager-subordinate dating relationships damage workgroup morale, create perceptions of favoritism, and can easily generate lawsuits for sexual harassment, retaliation, and wrongful termination.

If the relationship ends on a bad note, the subordinate may claim "quid pro quo" harassment. The subordinate can complain that he or she thought their job depended on the continuance of the relationship. Quid Pro Quo represents a form of harassment requiring a favor or interaction as a condition for employment, continuing employment, or in exchange for employment benefits (e.g., promotion, pay raise, etc.). et al, 2004) $)^{1}$ :

Some practical steps to guide managers on how to avoid risks of fraternization include the following (Heinze

- Review your company's policies on fraternization to maintain your currency. Most companies have employment guidelines specifically stating that managers are not permitted to date or pursue romantic or sexual relationships with employees whom they supervise directly or indirectly.

- $\quad$ Require all your subordinates to periodically review your firm's fraternization guidelines and resolution procedures.

- Direct your human resources department to resolve any current fraternization issues outstanding.

- Direct your employees who have a conflict of interest concern to describe the situation to a Human Resources Department contact and ask for guidance. Employees should always inform their employers when confronted with any situation that may be perceived as a conflict of interest, even if the employee doesn't believe the situation would violate employer guidelines.

- $\quad$ Address and resolve all new fraternization concerns immediately to lessen the chances of lawsuits.

- Investigate all complaints of favoritism, retaliation, wrongful termination, or sexual harassment for underlying signs of fraternization.

- Do not allow gossip to flourish and fuel unwarranted perceptions of favoritism that could, if uncontrolled, negatively impact your firm.

\section{CASE \#2: NEPOTISM}

\section{Case Facts}

Trish is the daughter of Effie who is an accounting manager at a company. Trish has a minor in accounting, so she meets the minimum qualifications for a job opening in the accounting department. Trish applies for a position through normal staffing procedures. Effie supervises Sherry who makes the hiring decisions for their department.

\footnotetext{
${ }^{1}$ As an additional reference, Schultz (2003) provides steps the employer can take to prevent legal liability stemming from fraternization.
} 
Sherry sees that Raul has also applied for the position. Raul has a Masters degree in accounting from a reputable school, and unlike Trish, has passed the CPA examination. Raul is a much stronger candidate. Effie drops a hint to Sherry that Sherry will be rewarded for hiring Trish.

\section{Discussion Guiding Questions}

- What is meant by the term nepotism?

- How is Effie acting in a manner that exhibits nepotism?

- How is Effie's nepotistic behavior hurting the company?

- How might Effie's nepotistic action hurt her? Trish?

- How could the conflict of interest problem have been prevented?

- As a high level manager within the organization, how would you address and resolve the nepotistic conflict of interest problem?

\section{Teaching Notes}

A nepotism type of conflict of interest exists when one uses a position of power or authority to influence the hiring or promotion process of a spouse, partner, sibling, child or other relative. This same philosophical view also prohibits supervising or directing the work of a subordinate who is a family member. Such a prohibition removes from the workplace any hint of nepotism. This prohibition is extremely important since a supervisor's division of loyalties between the employer's best interests and family generates overwhelming perceptions of favoritism among coworkers. It also introduces a bona fide risk of biased judgment and decision-making.

Effie is using her position to influence the hiring decision in favor of her daughter. The company should have policies and procedures in place to ensure that an employee does not use his or her position to exert influence to get a family member hired. Effie's loyalties appear to be divided between her employer's best interests and her daughter's best interests. Effie's action is hurting the company in the following ways:

- If successful, Effie's actions will result in the hiring of a less qualified employee. Hiring Raul would be best for the company.

- If Trish is hired, department-wide perceptions of favoritism that will hurt morale will likely occur.

- If Trish is hired, Sherry will be in an awkward position. Effie will effectively supervise and evaluate Trish. Trish and Effie will both also be in awkward positions.

Employees should avoid any nepotism type of activity whether in fact or in appearance that is adverse to the employer's best interests. Any such activity can significantly degrade workplace morale and result in internal turmoil. An employer's prohibition against undue positional influence or pressure to hire or promote relatives enables the company to focus efforts on hiring and promoting the best-qualified applicant without bias.

Some practical steps to guide managers on how to avoid risks of nepotism include:

- Review your company's policies on nepotism to maintain your currency. Most companies have employment guidelines specifically stating that employees are not permitted to take part in activities that could be construed as nepotistic.

- $\quad$ Require all your subordinates to periodically review your company's guidelines and resolution procedures involving nepotism to assure familiarity.

- $\quad$ Direct your human resources department to resolve any nepotistic issues which might be unresolved in a timely manner.

- Direct your employees who have a conflict of interest concern to describe the situation to a Human Resources Department contact and ask for guidance. Employees should always inform their employers when confronted with any situation that may be perceived as a conflict of interest, even if the employee doesn't believe the situation would violate employer guidelines. 
- Investigate, address, and resolve any new nepotistic conflicts of interest concerns (either real or apparent) immediately upon identification to lessen their repercussions.

- Do not allow gossip to flourish and fuel unwarranted perceptions of nepotism that could, if uncontrolled, negatively impact your organization.

\section{CASE \#3: RELATIVE OR FRIENDS EMPLOYED BY SUPPLIERS OR CUSTOMERS}

\section{Case Facts}

- Joe is responsible for identifying and approving a vendor for carpet cleaning services for their company's worldwide headquarters. Joe has narrowed the potential vendor list to two carpet cleaning companies: Bob's Carpet Cleaning, and Dan's Carpet Cleaning.

- $\quad$ Evaluation of Bob's Carpet Cleaning Company revealed that Bob recently acquired expensive, state of the art equipment enabling Bob to provide high quality, industrial carpet cleaning. In addition, Bob's Carpet Cleaning is both price and time competitive with all alternative cleaning operations available. Joe was excited about Bob's Carpet Cleaning Company and knew the company well because his wife, Sarah, is employed as the controller of Bob's Carpet Cleaning Company. Bob's Carpet Cleaning has a bonus incentive plan that (1) pays a finder's bonus to employees who find new customers, and (2) pays a bonus to employees based on profit sharing. Sarah intends to put in for a finder's bonus should her husband decide to select Bob's Carpet Cleaning Company as his company's carpet cleaning vendor. Sarah is also excited about the possibility of a larger profit sharing bonus that would likely result from the increased business.

- Dan's Carpet Cleaning, which has been used in the past, uses outdated, older equipment. Regardless, Dan's Carpet Cleaning is both price and time competitive.

- Joe decided to hire Bob's Carpet Cleaning Company as the sole carpet cleaning vendor for his company because of the anticipated higher quality of work associated with the newer equipment that would be used. Joe has not disclosed any information regarding his wife's employment to his company.

\section{Discussion Guiding Questions}

- Is there a conflict of interest problem? If so, is there a real conflict of interest or merely the appearance of one? If you feel that there is a conflict of interest, what is the immediate financial cost to Joe's company of this conflict? What is the immediate financial cost to Sarah's company of the conflict of interest?

- Why is the marriage between Joe and Sarah, and their employment positions, a cause for concern for both companies?

- What action(s) should Joe take to reduce or eliminate the conflict of interest? Is disclosure sufficient?

- If Joe disclosed Sarah's position with Bob's Carpet Cleaning Company, would a conflict of interest still exist?

- $\quad$ How could the conflict of interest problem have been prevented?

- As a high level manager within the organization, how would you address and resolve the conflict of interest problem?

\section{Teaching Notes}

If Joe did not formally disclose his wife's high-level employment with Bob's Carpet Cleaning Company, he has likely violated his employer's standards on conflict of interest and disclosure.

Most employers have a policy that employees avoid any activity that shows favoritism towards family members or the perception of such favoritism. Such behavior is considered disloyal or at odds with the best interests of the employer. Employees should always inform their managers when confronted with any situation that may be perceived as a conflict of interest, even if the employee doesn't believe the situation would actually result in a conflict of interest. 
To prevent the perception that Joe's recommendation was influenced by the possibility that he or his wife might somehow benefit from the vendor decision, Joe should have formally declared the relationship whether or not he believed a conflict existed. To prevent an actual or perceived conflict of interest, Joe's employer probably should have removed Joe from a decision-making role for the carpet cleaning decision.

Some practical steps managers can take to avoid risks associated with conflicts of interest when relatives or friends are employed by suppliers or customers include:

- Review your company's policies on conflict of interest to be sure that you are current on policies governing conflicts of interest involving relatives or friends. Most firms have policies and guidelines which address "relative or friends employed by suppliers or customers" types of conflict of interest. Be sure that disclosure issues are addressed. In many situations, publicizing the family/friend relationship will reduce or eliminate the perception of a conflict of interest. Other preventive options available to an employer should be identified such as transferring an employee, or changing the employee's responsibilities either temporarily or permanently.

- $\quad$ Require all your subordinates to periodically review your firm's policies, guidelines, and resolution procedures related to conflicts of interest involving relatives or friends.

- Direct your human resources department to resolve any such conflict of interest issues which might be unresolved in a timely manner.

- Direct your employees who have a conflict of interest concern to describe the situation to a Human Resources Department contact and ask for guidance. Employees should always inform their employers when confronted with any situation that may be perceived as a conflict of interest, even if the employee doesn't believe the situation would violate employer guidelines.

- Investigate, address, and resolve any conflict of interest concerns (either real or apparent) immediately upon identification to lessen their repercussions.

- Do not allow gossip to flourish and fuel unwarranted perceptions of favoritism that could, if uncontrolled, negatively impact your organization.

\section{SUMMARY}

These teaching cases stress that employees should work proactively to prevent and resolve conflict of interest issues. Failure to take such issues seriously can have dire consequences. Be sure to review your company's policies on conflict of interest, which should be available in the Human Resources Department. If an employee is uncertain about whether a conflict exists, the employee should describe the situation to a Human Resources Department contact and ask for guidance. Employees should always inform their employers when confronted with any situation that may be perceived as a conflict of interest, even if the employee doesn't believe the situation would violate employer guidelines. If the employee or employer should conclude that there is a conflict of interest, the employee must either relinquish the conflicting activity or resign the position. Most of the time, however, a solution is readily available. For example, the employee can be transferred or removed from a decision-making role on a temporary basis.

Employees are expected to devote their best efforts and full attention to the performance of their duties. They are expected to use good judgment, adhere to high ethical standards, and avoid situations that create an actual or perceived conflict between the employees' personal interests and the interests of the employer.

\section{REFERENCES}

1. Heinze, T. C., T. K. Kizirian, and W. Leese. 2005. Fraternization in Accounting Firms: A Case Study. Journal of College Teaching and Learning. Volume 1. Number 12. December 2004.

2. Schultz, Vicki (2003), The Sanitized Workplace. Yale Law Journal, Volume 112; Issue 8, pp. 2061-2073. 


\section{NOTES}

